\title{
OPEN Author Correction: Insight on Tafel slopes from a microkinetic analysis of aqueous electrocatalysis for energy conversion
}

\author{
Tatsuya Shinagawa, Angel T. Garcia-Esparza \& Kazuhiro Takanabe \\ Correction to: Scientific Reports https://doi.org/10.1038/srep13801, published online 08 September 2015
}

In this Article, the authors did not originally include an assumption justifying why the activity of species, $a_{i}$, (dimensionless) is used to describe the rates of the reactions. This is because these terms included standard concentration $c^{0}$ (which is $1 \mathrm{M}$ ).

Therefore, in the Results and Discussion,

“The constants include Faraday's constant, $\mathrm{F}=96500 \mathrm{C} \mathrm{mol}^{-1}$, the gas constant, $\mathrm{R}=8.314 \mathrm{~J} \mathrm{~mol}^{-1} \mathrm{~K}^{-1}$, temperature $T$, the electron transfer coefficient, $\alpha=0.5$, and the surface area of the electrode, A."

should read:

“The constants include Faraday's constant, $\mathrm{F}=96500 \mathrm{C} \mathrm{mol}^{-1}$, the gas constant, $\mathrm{R}=8.314 \mathrm{~J} \mathrm{~mol}^{-1} \mathrm{~K}^{-1}$, temperature $T$, the electron transfer coefficient, $\alpha=0.5$, and the surface area of the electrode, A. The activity of the species $i$ is given by $a_{i}=\gamma_{\mathrm{i}} c_{\mathrm{i}} / c^{\circ}$, where $\gamma_{\mathrm{i}}$ is the mean activity coefficient, $c_{\mathrm{i}}$ is the concentration, and $c^{\circ}$ is the standard concentration. Since the standard concentration is $1 \mathrm{M}$, the effective concentration can be simplified into $a_{i} c^{\circ}=$ $a_{i}$ and this is used hereafter."

This change does not affect conclusions of the Article.

(c) (i) Open Access This article is licensed under a Creative Commons Attribution 4.0 International License, which permits use, sharing, adaptation, distribution and reproduction in any medium or format, as long as you give appropriate credit to the original author(s) and the source, provide a link to the Creative Commons license, and indicate if changes were made. The images or other third party material in this article are included in the article's Creative Commons license, unless indicated otherwise in a credit line to the material. If material is not included in the article's Creative Commons license and your intended use is not permitted by statutory regulation or exceeds the permitted use, you will need to obtain permission directly from the copyright holder. To view a copy of this license, visit http://creativecommons.org/licenses/by/4.0/.

(C) The Author(s) 2020 